Journal of Music, Technology \& Education

Volume 10 Number 1, p117-138

\title{
Music technology, education and maps: The use of geospatial technology and data to inform music education research
}

\section{Ross Purves}

Education Division, School of Applied Social Sciences, Faculty of Health \& Life Sciences, De Montfort University

\begin{abstract}
Recent developments in geographical information systems and geospatial statistics, together with greater access to large, fine-resolution 'geocoded' data sets, are transforming environmental, social and economic research. Over the past decade, there has been a small, but growing application of these techniques within the fields of music making, music education and music research. This article begins by offering a brief overview of some of the developments as a whole. It goes on to offer a detailed treatment of a series of geospatial statistical techniques which, it is hoped, may be applicable within a wide range of music and music education research fields. These techniques are illustrated through references to a deviant idiographic case study dealing with instrumental tuition provided by one English local government area (local authority) between 2003 and 2010. The case study draws on analyses of detailed anonymized participant records $(\mathrm{n}=6063)$ using, amongst other techniques, location quotients, tests for spatial autocorrelation and distinct distributions and 'global' and 'local' regression models. The article will demonstrate how these techniques can be applied using open-source software and freely available census, government and cartographic data.
\end{abstract}

\section{Key words}

open source; geographical information systems; geospatial statistical analysis; deviant idiographic case study; English local authority; instrumental tuition; music education 


\section{Introduction}

The past decade or so has witnessed developments in what might be termed 'geospatially informed' research and creative work within music. Some of this work has resulted in logical extensions of existing music technology processes and techniques. Other efforts have brought to bear combinations of technological tools already common in other domains (e.g. handheld global positioning system [GPS] units, geographical information systems (GIS), 'big' data sets and statistical programming languages) on a variety of creative and research challenges relating to music. It is possible to view these developments as part of a broader trend towards reconceptualizing 'music technology' as 'a means for researching, monitoring, recording, enabling, celebrating and promoting musical participation and development, as well as emotional engagement through music and sound' (Himonides and Purves 2010: 137). Within this article, I want to argue that the hardware and software that now enable music practitioners and researchers to incorporate a sense of 'place' and 'space' into their work should be regarded as viable, flexible and increasingly mainstream forms of music technology. Moreover, I wish to suggest that the field of music education, in particular, has much to gain from their widespread adoption.

I begin by offering a brief overview of some of the developments in this field as a whole, before offering a more detailed treatment of a series of geospatial statistical techniques which, it is hoped, may be applicable within a wide range of music research fields. These techniques are illustrated with reference to a large case study of young people's access to publicly funded instrumental music tuition within one English local government area.

\section{Mapping the field: illustrative examples of existing geospatially informed work within music making and research}

Many practitioners active in this area have sought to exploit spatial information by extending data/sound capture methods already in use within technology- mediated music composition and research. Amongst the best-known creative examples of this work are the sound-based musical genres of 'soundmaps' and 'soundwalks' (see Prebble [2010] and Barber [2015] for links to many interactive, online examples of these genres). Such compositions often involve logging the geographical position of sounds recorded 'on location' and subsequently replaying these 'virtually' as part of a sonic landscape on a digital map. The listener is free to move between the sounds by navigating around the map with a computer mouse, etc., sampling the constantly shifting texture created as sounds 'emerge' and 'recede'. One composer and sound artist active in this area is the Scottish musician Stollery, who 
described his 2005 soundmap composition 'Gordon Soundscape' as an attempt to examine 'our response to our aural environment, our sense of belonging to a particular place and our ability to remember through sound' (2005, online).

On a technical level, work has been done to try to integrate the processes of capturing and analysing musical and spatial information. For instance, Knopke (2005) proposed a web crawler system for music files which augmented normal file 'metadata' with country of origin tags derived from IP addresses. This system was capable of identifying hitherto hidden regional trends in music file types and highlighted relationships between the availability of online music and population density. More recently, efforts have focused on the spatial analysis of listening habits using location-tagged microblogging data from Twitter. Moore et al. conclude that such work has the potential to 'uncover examples of how musical taste conforms to or transcends geography, language, and culture' (2014: 6). Sebastian (2015) demonstrated how geospatial data collected using a handheld GPS can enrich ethnomusicological fieldwork. Patterns of busking around Jackson Square, New Orleans were documented by plotting the observed locations of musicians using the Google Earth interface. These plots were subsequently enriched further through additional mapping layers showing population density, city zoning, the location of night clubs and even the average prices charged at local restaurants.

A related trend is the growing interest in 'big data' within music research (see Himonides 2016). A proportion of these big data sets already come 'geocoded' to a greater or lesser degree, i.e. individual records have been tagged with geographical coordinates in the form of grid references, latitudes/ longitudes or postal codes (Lloyd 2010). One example is the 'Million Musical Tweets Dataset' (Hauger et al. 2013). This exploited Twitter's inherent potential to log location information as part of meta tags published with each tweet. Another example is the data set generated by the BBC's 'How Musical Are You?' project which ran between 2011 and 2013. This data set, containing 147,633 participant responses, was used as the basis of Müllensiefen et al.'s (2014) analysis of 'musical sophistication' in the general UK population. Since participants' approximate home locations were known (stored in the form of truncated postal codes), the researchers were able to break down their results to the level of the local government area. In a further example, Born and Devine (2015) analysed university admissions data for 'traditional music' and 'music technology' degrees offered by twelve UK universities for the period 2007-2012. Partly through the use of postal-codereferenced sociodemographic data included in this set, the researchers highlighted differences in the backgrounds of students studying these related, yet distinct, academic areas. They found that the majority of students taking the 'traditional music' degrees were 
from 'regions most likely to participate in [higher education] and showing greatest relative advantage' (2015: 152). In contrast, around half of the students taking 'music technology' degrees were from areas characterized as exhibiting more pronounced levels of educational disadvantage, as assessed through lower rates of university progression.

\section{Specific applications in music education}

It is evident from Born and Devine's example that music education stands to benefit in particular from the application of geospatial technologies. Literature in this area has tended to fall into one of the two categories, relating to geospatial technology's use either as a pedagogical tool or as a means of evaluating educational provision. In the first category, it is probably in the areas of world music and ethnomusicology education where these tools have gained maximum use to date. Lund (2007) offered an excellent review of much early work along these lines, concluding that the use of GISs had the potential to illustrate to students 'the interrelated complexities of music, musicians, audiences, and the world in which they thrive' (266). A well-established project between the earth sciences and music education departments at Penn State University adopts a similar philosophy and has generated a large number of freely available, Google Earth-linked teaching resources and sound files for school teachers (LaJeunesse 2011; Clements and Guertin 2016).

A second, smaller and more recent category of literature has made use of geospatial technologies to evaluate aspects of music education provision, with specific regard for access and inclusion. Born and Devine's (2015) study certainly fits into this category. A further example may be drawn from the UK Charity Youth Music's large-scale, grant-making programme 'Musical Inclusion', active between 2012 and 2015 (Deane et al. 2015). As a grant holder in this programme, the Cornwall Youth Music Action Zone commissioned research intended to identify 'cold spots' in provision, i.e. areas of the county where a wide range of challenging social, economic and educational circumstances were perceived to impact negatively on young people's ability to engage in musical activity (Stone by Stone 2012). The adopted methodology involved combining a range of geocoded data on deprivation (in the form of the English Government's 2010 Indices of Multiple Deprivation [IMD]), the number of local projects funded by Arts Council England and the locations of existing youth and community music projects. A choropleth map (see definition below) of these summed factors revealed that the 'coldest' spot in Cornwall in fact lay geographically immediately to the west of the 'warmest' spot. Despite living less than ten miles apart, the young people inhabiting these two areas had markedly different levels of local musical opportunity. In another example, Hille (2015) investigated a German youth musical inclusion programme based in North Rhine-Westphalia. Like Youth Music's programme, the Jedem 
Kind ein Instrument (an instrument for every child) (JeKi) project sought to give young people from poorer backgrounds enhanced musical engagement opportunities. Hille used geodesic distance calculations derived from postal code coordinates to link German government socio-economic survey data to the locations of schools participating in the JeKi programme. This lent support to the main finding that JeKi had been successful in increasing participation amongst young people from families with a household income below the median.

The examples from Stone by Stone (2012) and Hille (2015) are notable not only for their use of geospatial analysis, but also for their exploitation of publicly available, geocoded, socioeconomic data sets. From a more general perspective, research in the social sciences has recently been characterized as undergoing a 'spatial turn' (Fielding and Fielding 2015), whereby quantitative and qualitative research studies in many disciplines have been enriched through the use of geocoded 'big data'. Available in ever larger quantities and often conveniently and freely accessible online, these data sets typically emanate from official census exercises or other government surveys of human and environmental factors. They are made available at sufficiently detailed levels of geographical resolution to inform local, place-based analysis. The provision of this data can itself be regarded as part of an international trend for governments to make use of spatially referenced data to target funding and policy initiatives in highly localized ways (e.g. see Goodwin 2004; Pill 2007). Such targeting is typically done with a view to ameliorating the impacts of perceived socioeconomic disadvantage in these local areas. Therefore, it seems likely that, in the future, making use of this data in order to evaluate music education programmes intended to reach communities regarded as 'disadvantaged' will become the norm.

\section{The rise of open-source geospatial software tools}

The growth in the availability of large, geocoded data sets has been paralleled with the growth of free and open-source software to support geospatial analysis. The potential of open-source software to disrupt the mainstream music technology field is well documented (e.g. Purves 2012), and a similar situation has occurred with GISs technology in recent years.

The workhorse of geospatial research is the 'GIS', a software environment in which geographical data can be displayed, processed and analysed. Recently, highly sophisticated open-source GIS packages have emerged, freeing researchers from reliance on expensive commercial software. Within the case study presented below, extensive use was made of 
QGIS (qgis.org). It is thought that this open-source GIS now has a userbase in the hundreds of thousands (Sutton 2016). Although some geospatial analysis is possible within QGIS, it is often more convenient to use third-party, specialist tools. In the illustrative case study, Moran's I, Syrjala, 'global' regression and 'local' geographically weighted regression (GWR) calculations were conducted using $R$ (r-project.org), the well-known, open-source, statistical programming environment. Additional packages for $R$ provide easy access to these geospatial tests.

With geospatial research often making use of very large, potentially ethically sensitive data sets, the use of a robust, flexible and secure database management system is important. In the following case study, all data were stored using MySQL Community Edition (dev.mysql.com), free software also available under the GNU public license. Using structured query language (SQL), one can often complete basic geospatial processing tasks within the database, lessening the need to export data to $R$. For example, in the case study, the location quotient (LQ) examples were all calculated directly within MySQL. For more sophisticated work, it is possible to have QGIS, R and MySQL communicate and share data directly using various third-party plugins and QGIS's 'processing toolbox'. On the other hand, it is often more simple and convenient to exchange data between them via commaseparated text files.

\section{Ethical considerations}

It is essential to consider ethical issues relating to the handling of large quantities of geocoded data, particular when this might inadvertently describe or identify individuals. There is, as Martin notes, a 'continual tension between the protection of individual rights and the need for high quality information' (2004: 2). Fundamentally, Exeter et al. (2014) argue that much of the analytical power of geospatial techniques comes from the ability to datamatch individual, geocoded records with large pre-existing data sets. However, the resulting 'mash-ups' have the potential to 'together reveal more as a whole than the sum of the individual parts' (Exeter et al. 2014: 2). As more data become available, and as the data matching, analysis and visualization processes become more sophisticated, concerns have been raised regarding the implications for data protection. Even when working with anonymized sources, it is relatively common for geospatial data to include what Exeter et al. call 'proxy identifiers'. These data, which describe characteristics such as age and gender, have the theoretical potential to be data-matched and aggregated with 'direct identifiers' such as postal code, effectively 'reverse-geocoding' and retrieving formerly anonymized data at the individual level (Van den Eynden et al. 2011). 
So-called geoprivacy should therefore be considered as an extension of existing legal requirements (e.g. the 1998 Data Protection Act in the United Kingdom) and ethical research frameworks (e.g. BERA 2011). In the illustrative case study which follows, none of the findings are presented in ways whereby individual participant data might be inferred. Instead, data are aggregated at the spatial resolution of LSOA or higher (Exeter et al. 2014).

\section{Introducing the case study: a local authority music service in England}

This article draws on findings from a large idiographic case study of publicly subsidized instrumental tuition provision and its take-up within one English local government area (local authority). This study is introduced in more detail elsewhere (Purves 2016), and the main intention below is to highlight some key findings as a means of illustrating how geospatial tools and techniques might benefit those working in music and music education research. Nonetheless, it is necessary to offer a brief introduction to the case study. It is also important to note that whilst the locale was England, equivalent sources of public data, postal code and geocoding systems exist in many other countries, with more detailed sources of data being made available all the time.

Beginning in the 1940s, many UK local authorities appointed teams of 'peripatetic' music teachers, whose role was to travel between schools providing instrumental tuition alongside any music education that might be part of the school's classroom curriculum. In addition, local youth orchestras, wind bands, choirs and jazz orchestras were instituted, with rehearsals taking place in evenings and at weekends. This provision of instrumental tuition has always been a non-statutory responsibility for local authorities. As a result, there have been frequent fluctuations in public funding, and demand for tuition has rarely been met by supply.

Over the decades, many world-class musicians emerged from the music service system. Yet whilst there were undoubtedly opportunities and resulting personal and professional successes for some, there has also been widespread acknowledgement that these might have come at the expense of opportunities for the many. For instance, an oft-repeated estimate was that only around 10 per cent of the school population was in receipt of local authority instrumental tuition at any one time (e.g. Mainwaring 1951; Hallam 1985; Thomson 1989). By the 1990s, there were signs that music services were introducing new models of 
tuition with the potential to widen access. However, these developments were mitigated by reduced levels of local government subsidy (Hallam and Prince 2000).

In the case of the anonymous local authority referred to below, a particularly challenging range of local social, cultural and economic circumstances led to its instrumental music service receiving unparalleled levels of national government funding between 1998 and 2011 as part of the 'Music Standards Fund'. The then government's intention for this funding was to address the perceived decline in schools' instrumental tuition during the 1990s, to widen access and to make this provision more inclusive. This development came at a time of unprecedented political interest in all aspects of music making and learning.

Since this local authority had received such significant investment on the basis of its particular circumstances, it offered a valuable 'deviant', idiographic study (George and Bennett 2005; Mitchell 2006) of the impacts of this government investment. A key objective of the research was to establish whether a range of 'hidden barriers' to young people's ability to access this provision were overcome by the additional resources available. These barriers, derived from a parallel historical documentary study of the local authority music service literature, embraced a variety of underlying socio-economic, environmental and geographical factors.

The case-study music service consented to provide its entire database of 12,448 instrumental tuition records covering September 2003 to November 2010, anonymized through the removal of pupil names. A clustering process revealed that these records were, in reality, associated with 6063 individual young people (on the basis of valid postal codes and distinct combinations of birth date, gender and ethnicity). With tuition records clustered, it was possible to infer additional information about each pupil, such as the total time spent learning formally with the music service, the total number of instruments studied and the primary/secondary schools attended during periods of tuition. Additionally, pupils' postal codes allowed their home locations to be pinpointed to street level and cross-referenced with geocoded public data sets, as outlined above.

\section{The UK Postcode and matters of geospatial resolution}

In the United Kingdom, postal codes are termed 'postcodes'1. This system divides the country into 'areas', 'districts', 'sectors' and 'units' (UK Data Service 2010). The last of these

\footnotetext{
${ }^{1}$ A summary of postal code systems in many countries of the world can be found at http://www.grcdi.nl/gsb/summary_\%20postal\%20code\%20synonyms.html.
} 
(corresponding to the final two characters in a complete postcode) break the country down into very small areas. Each unit contains around fifteen residential or business addresses. The precise latitudes and longitudes of these units are held, allowing geographical placement to a resolution of up to $1 \mathrm{~m} 2$ from postcode alone.

However, since postcodes (and other boundary systems such as electoral wards) can be changed to reflect changing patterns of economic and residential behaviour, they are not suitable as a long-term reference system for collating and comparing socio-demographic data over time. The solution in the United Kingdom was for the Office for National Statistics to introduce 'Output Areas' (OA) during the 2001 Census. These enable longer term comparisons to be made (UK Data Service 2010). OA are grouped further into 'middle level super output areas' (MSOA) and 'lower level super output areas' (LSOA). The latter, which typically each have a population of around 1500 residents, are used extensively within geospatial research since many official government data sets are available aggregated and geocoded at this level of spatial resolution. Case study music service pupils' postcodes were linked to their home OA, LSOA and MSOA via cross-references with the UK Data Service's (2010) 'Office for National Statistics Postcode Directory' (ONSPD).

\section{The modifiable areal unit problem}

Working with areally aggregated spatial data has challenges. In particular, the modifiable areal unit problem (MAUP) can impact negatively on attempts to analyse aggregated data (Fotheringham et al. 2002). The MAUP can result in distorted interpretations of findings when the same spatial data is analysed using an alternative areal level or shape. For instance, one may achieve a statistically significant test result when grouping spatial data by LSOA, but a non-significant result when grouping the same data by an alternative spatial unit, such as postcode district or electoral ward. Many strategies for managing the MAUP have been proposed but a basic requirement is to ensure that spatial statistical tests are conducted at a minimum of two different areal resolutions (Qiu and Wu 2011). To this end, the results presented below have all been checked for statistical significance at both the LSOA level and either OA or MSOA level, depending on the spatial resolution of the source data. Only those results which could be reproduced at two spatial resolutions were taken as evidence of a genuine effect.

\section{Case study results: illustrating so key geospatial analysis techniques}




\section{LQ and choropleth maps}

The LQ was introduced in 1939 as a tool for economic analysis (St John and Richardson 1996). Originally intended to highlight local areas with concentrations or absences of a particular industrial sector in relation to the regional or national situation, it has since been used in many other areas of geographical and social sciences research, for instance health and crime analysis.

In the case study, LQs offer a useful means of assessing the levels of concentration of music service pupils in different LSOAs, based on various criteria, e.g. players of particular instruments or young people from particular ethnic backgrounds. The total population of young people varied from LSOA to LSOA, and simply counting the number of participants living in each LSOA who meet the given criteria would have been too simplistic, since this would not take into account areas inhabited by fewer children to begin with (e.g. concentrations of small flats inhabited by young professionals or retired people). LQs are sensitive to this because they are calculated using the total number of young people living in an LSOA as a divisor. Moreover, they enabled the comparison of local concentrations of these participants with the equivalent number in the population as a whole.

As an example of the technique, the level of termly participation within each LSOA was called the 'Service Reach Location Quotient' (SRLQ). This gave an accurate representation of the proportion of young people in each LSOA who engaged with music service tuition each term. National comparison data for this calculation were drawn from the 2005 survey of local authority music services undertaken for the Department for Education by Hallam et al. (2005). SRLQ scores were calculated for each LSOA in the case study authority using Equation 1:

$$
S R L Q=\frac{p_{\text {tuition }} / p_{\text {all }}}{P_{\text {Hallam }} / P_{\text {all }}}
$$

Here $p_{\text {tuition }}$ refers to all young people receiving music service tuition in an LSOA, and $p_{\text {all }}$ refers to all young people aged 8-16 in that LSOA at the time of the 2001 UK Census (Table CS001). $P_{\text {Hallam }}$ refers to the total number of young people in KS2-KS4 receiving instrumental tuition nationally on 1 February 2005 (Hallam et al. 2005: 99). $P_{\text {all }}$ refers to the total school population aged 7-16 in England in January 2005 (SFR42/2005, Table 14). The resulting SRLQ scores were averaged over the 21 academic terms covered by the case 
study data, with the mean values then plotted as a 'choropleth map' of the local authority LSOAs (Figure 1).

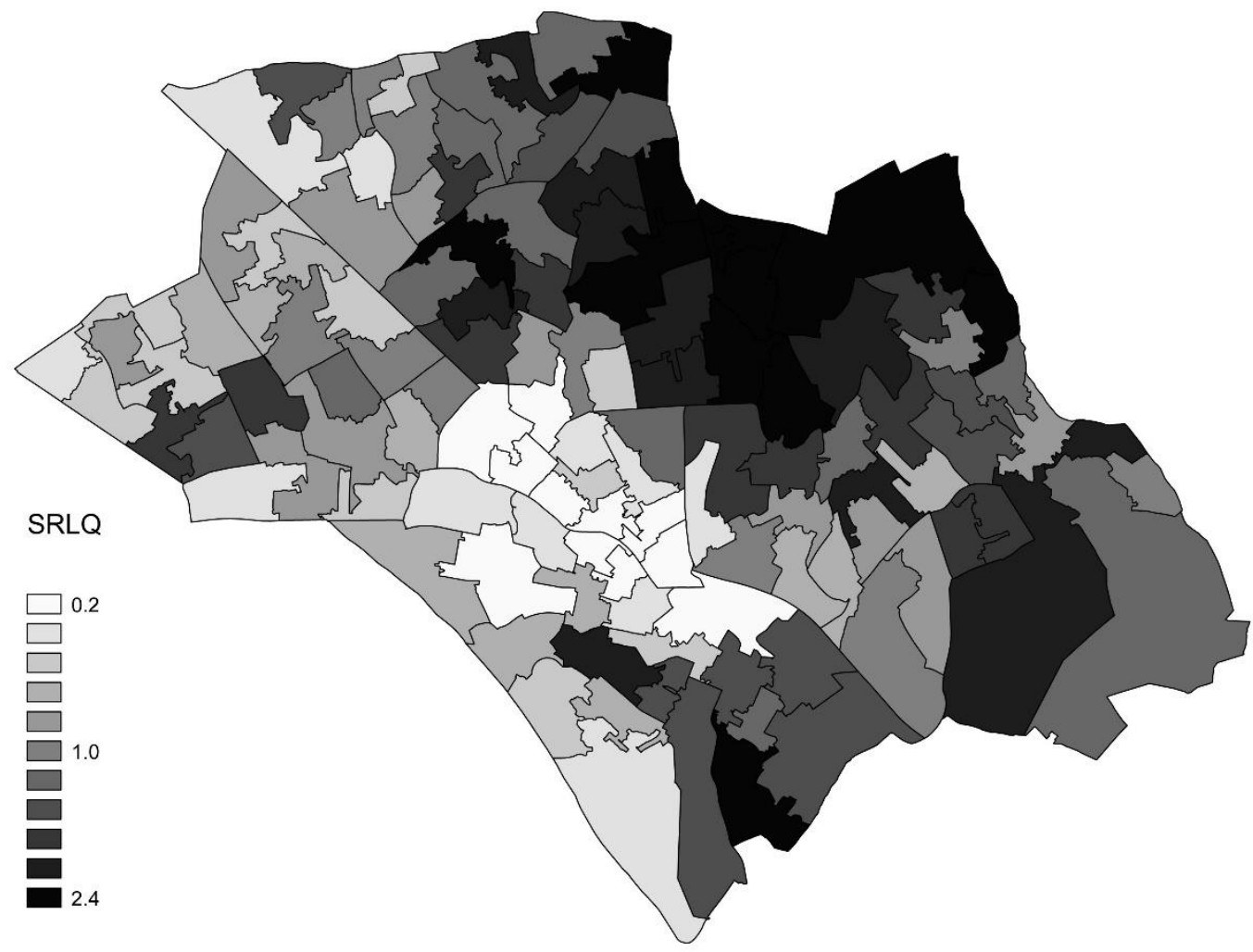

Figure 1: A choropleth plot of mean SRLQ scores for each LSOA within the case study local authority. Increasingly lighter shading indicates below-national levels of participation (SRLQ values of $<1$ ), whilst increasingly darker shading indicates above-national levels (SRLQ values of $>1$ ).

Choropleth maps divide a study area into areal units and then colour or shade each of these units to give a visual representation of change in data values (St John and Richardson 1996). Data are grouped into ranges of values, and each range is allocated a particular colour designation. All areas on the map with data within each range are then shaded or coloured similarly (Lloyd 2010).

An SRLQ score of close to 1.0 indicates that the number of participants as a ratio of all young people living within the LSOA was in line with the equivalent ratio in the national population. Scores of $<1.0$ indicate that the number of participants in the local LSOA was less than the equivalent national figure, whereas scores of $>1.0$ indicate that participation was greater than in the population as a whole. In general, it is clear that LSOAs on the south-west of the case study local authority were inhabited by far fewer music service pupils whilst areas in the north-east were often home to far higher numbers of participants as scores of $>2.0$ demonstrate. The clustering of SRLQ scores in adjacent LSOAs is visually 
quite clear in Figure 1, but a Moran's / test allows the researcher to be sure that such visual clustering is evidenced statistically (Lloyd 2010).

\section{Moran's / test}

Tobler's famous first law of geography states that 'everything is related to everything else, but near things are more related than distant things' (1970: 234). This implies that data collected from nearby geographical locations were likely to have more in common than data collected from locations further apart. Data sets exhibiting this quality are said to be spatially autocorrelated, i.e. significantly correlated with themselves. Although it is often possible to identify spatial autocorrelation through visual inspection of a choropleth map, this is not a foolproof method and, in any case, does not offer an accurate measure of the extent of this autocorrelation.

Moran's I offers a formal test for the presence of autocorrelation (Lloyd 2010). I is calculated as a coefficient with values ranging between -1.0 and +1.0 . Values for $/$ that are nearer to -1.0 give an indication that the data are highly dispersed and that consequently there is a high degree of negative spatial autocorrelation. This means that neighbouring values in the data tend to differ. Values nearer to +1.0 indicate stronger levels of positive spatial autocorrelation, meaning that neighbouring values in the data are generally similar. A value of close to 0.0 indicates no clear structure either way, i.e. values in the data are largely randomly distributed across the space. Moran's / tests were implemented through the use of the function moran.test from the $R$ package spdep (Bivand et al. 2013; Bivand and Piras 2015).

A Moran's I test confirmed the presence of spatial autocorrelation in the SRLQ scores $(I=$ $\left.0.55 ; p<1 \times 10^{-15}\right)$. A confirmatory Moran's $/$ test at the OA level also produced a statistically significant result $\left(I=0.24 ; p<1 \times 10^{-15}\right)$. Taken together, these values for $I$ indicate that the strong spatial autocorrelation apparent visually in Figure 1 was not likely to be due to chance variation or to the MAUP. Overall, it appeared that the case study local authority was effectively 'bisected' by a line extended from the north-west tip to the southeast side. This 'line' is, in fact, a major inter-city railway, prompting reminiscence of the old adage about 'living on the wrong side of the tracks':

In 19th- and early-20th-century America, railroad tracks divided a city or town. On one side was the middle- and upper-class residential and commercial area. On the other were factories and residential shacks and tenements. Since residents of the 
former made class distinctions and applied appropriate language, anyone from the other part of town came from the wrong side of the tracks. (Price 2011, online)

With this adage in mind, it was important to establish whether this bisection was dictated by socio-economic variation. To this end, the Syrjala test was used to determine whether the distribution of music service pupils' homes was related to the town's prevailing socioeconomic landscape.

\section{Syrjala test}

This non-parametric statistical test was developed by Syrjala (1996) to compare the values of two spatial data sets (e.g. of counts or densities) which share a common set of coordinates. It has subsequently been implemented in the $R$ package ecespa by BlancoMoreno and de la Cruz Rot (2015). The test functions by making comparisons of both quantities and locations in order to provide an assessment of whether the two data sets share a common spatial distribution. It makes no assumptions regarding the distributions of the samples to be compared, beyond the fact that they must be equal in size. Further advantages are that it remains robust when samples include a few extreme values (Barroso et al. 2004) and is stringent in rejecting the null hypothesis (Sarkar et al. 2005). Thus, one may have confidence when the test indicates a statistically significant result.

The Syrjala test statistic is denoted as $\Psi$. The smaller $\Psi$, the more similar the spatial distributions of the two sample sets. When $\Psi$ is large, the difference between the two sets is greater. Significance is calculated using a permutation method whereby random pairs of sample points from each data set are swapped and the test repeatedly recomputed. The resulting $p$ denotes the proportion of recomputed, randomized tests in which the resulting $\Psi$ is greater-than-or-equal-to the observed $\Psi$. As in many other statistical tests, larger values for $p$ indicate that differences between the distributions of the two data sets are not statistically significant (McAdam et al. 2010). Recent increases in computing speed mean that it is now common for researchers to specify 9999 permutations (Huber et al. 2014; Berry et al. 2015).

With regards to the case study, the comparison data set drew on income deprivation data from 2010 edition of the English 'IMD'. The test statistic $\Psi$ was small (0.0393) and nonsignificant $(p=0.109)$. We may therefore conclude that these data sets are drawn from the same spatial distribution and that prevailing socio-economic conditions in the local authority were strongly related to music service tuition take-up. 


\section{Constructing a 'global' regression model}

Whilst the Syrjala test results established a clear link between the home locations of case study music service pupils and spatial patterns of income deprivation in the local authority, this test is not designed to shed light on why this link may have come about. To explore this link further, a series of exploratory multivariate 'global' regression models were developed. These helped to identify which socio-economic factors were most strongly associated with tuition take-up.

The term 'global' regression is used here to acknowledge that alternative, and potentially more nuanced, 'local' regression methods have now emerged within geospatial research (Fotheringham et al. 2002). Global regression models are those adopting the traditional 'ordinary least-squares' approach, in which the relationship between predictor variables and outcome variable remains 'fixed' across a geographical study area. Local regression models differ in that the coefficients representing the relationship between predictors and outcome variable are free to vary according to their spatial location in the geographical study area. Both of these approaches have their advantages and disadvantages, and methods are now available to enable researchers to make informed choices between them (Qiu and Wu 2011). For illustrative purposes, case study examples of both approaches are offered below, beginning with three global models and ending with a local model.

A wide variety of 'proxy variables' were initially explored as predictors for this global model, with 'all subsets variable selection' being used to assess which combination produced the best $R^{2}$ score, and thus best explained the variance in the average SRLQ scores (Field et al. 2013; see also the $R$ package leaps). Post hoc variance inflation factor tests were employed (using the $R$ package car) to ensure that the observed regression coefficients were accurate and not overly distorted by multicollinearity. Table 1 offers the final model for SRLQ scores; this can explain over 60 per cent of variance in these data.

Table 1: Global regression model featuring CYPSubDomScore, PC_DegHolders and PC_NonWhiteBritish as predictor variables and SRLQ as outcome variable.

\begin{tabular}{|l|l|l|l|l|l|l|}
\hline & Estimate & $\begin{array}{l}\text { Standardize } \\
\mathbf{d} \text { estimate }\end{array}$ & $\begin{array}{l}\text { Per cent } \\
\text { of } \boldsymbol{R}^{2} \text { (LMG } \\
\text { test) }\end{array}$ & $\begin{array}{l}\text { Standard } \\
\text { error }\end{array}$ & $\boldsymbol{t}$ value & $\boldsymbol{p}$ \\
\hline (Intercept) & 1.44203 & & & 0.13715 & 10.51 & $<1 \times 10^{-15}$ \\
\hline CYPSubDomScore & -0.01095 & -0.326 & 19 & 0.00226 & -4.85 & $<1 \times 10^{-5}$ \\
\hline PC_DegHolders & 0.02053 & 0.208 & 8 & 0.00646 & 3.18 & $<0.01$ \\
\hline
\end{tabular}




\begin{tabular}{|l|l|l|l|l|l|l|}
\hline PC_NonWhiteBritish & -0.01377 & -0.542 & 33 & 0.00153 & -8.99 & $<1 \times 10^{-14}$ \\
\hline
\end{tabular}

Residual standard error for model: 0.312 on 117 degrees of freedom; $R^{2}$ for model: $0.601 ; F$ statistic for model: 58.9 on 3 and $117 \mathrm{df}, p<1 \times 10^{-15}$.

'CYPSubDomScore' refers to an official measure of educational deprivation, produced as a constituent component of the English Indices of Deprivation 2010 (McLennan et al. 2011). Higher scores represent higher prevalence of school absence, school drop-out and low educational attainment. 'PC_DegHolders' refers to percentage of local adults holding university degrees, drawn from Table UV24 of the 2001 UK Census. 'PC_NonWhiteBritish' refers to the percentage of the LSOA population hailing from non-White British ethnic backgrounds. This was again drawn from 2001 UK census data (Table UV09). To reiterate an important general point made earlier, these open access government data sets were feasible and convenient to use in these kinds of models because they are aggregated and geocoded at LSOA resolution. They were thus readily compatible with the SRLQ calculations outlined earlier.

Of the three proxy predictor variables, PC_NonWhiteBritish explained the most variance (33 per cent of the total $R^{2}$ according to a post hoc Lindeman- Merenda-Gold (LMG) test [Grömping 2006; see also the relaimpo $\mathrm{R}$ package]). As the percentage of non-White British people in the LSOA rose, the number of young people undertaking music service tuition decreased. A similar, albeit less pronounced negative relationship was found between SRLQ and CYPSubDomScore. PC_DegHolders makes a positive, albeit smaller still contribution, indicating that areas inhabited by more graduates also tended to have greater levels of instrumental tuition take-up. Importantly, all three of these variables correlate at statistically significant $(p<0.001)$ medium or high levels with IMD2010 income deprivation figures (CYPSubDomScore: $r=0.71$; PC_DegHolders: $r=-0.44$; PC_NonWhiteBritish: $r=0.69$ ).

Overall, Table 1 tells quite a clear story: Instrumental tuition was taken up more widely in case study areas populated by high numbers of degree holders and white British people, whose children achieved better results in school examinations, exhibited lower levels of school absence and were more likely to stay on in post-compulsory education. Moreover, given the results of the Syrjala test above - and since all three of the underlying proxy variables correlate significantly with income deprivation - these results illustrate how various socio-economic factors may cohere, potentially influencing the ability of young people to access the instrumental learning opportunities available to them. In theoretical terms, this 
complex coherence is a reminder of the salience of familial accrual of social, financial and cultural capital as a means of overcoming these kinds of barriers. Parcel and Hendrix (2014) take these Bourdieusian concepts as the starting point for exploring 'parental investment frameworks'. By applying these frameworks, argue Parcel and Hendrix, some parents are able to actively prepare their children to 'navigate institutional settings, to be perceived favourably by teachers, and to see their own place in the status hierarchy as privileged' (363). In practical terms, these kinds of investments can result in 'resource boosters', defined as 'favourable conditions both at home and at school' (Parcel and Dufur 2001: 888).

\section{Bespoke applications: An example using the Google Maps application programming interface and 'scraped' web data}

Literature dealing with young people's access to local authority music service tuition has often highlighted concerns that pupils can be deterred from continuing their lessons in cases where they live farther from school or where they play a large or heavy instrument (e.g. Cleave and Dust 1989; Ofsted 2004). Vehicle ownership may well thus be a very practical example of what Parcel and Dufur (2001) define as a 'resource booster', leading to 'favourable conditions'. Beginning in May 2004, the UK charity Youth Music's Endangered Species scheme provided funding to music services to purchase stocks of instruments considered to be at risk of 'dying out' due to low take-up by young players (Artservice 2005, 2006). Following the scheme's launch, much was made in the media of how many of the instruments on the 'endangered list' were heavy and cumbersome to transport. Prominent musicians and music educators were asked to comment:

Large instruments can be a problem - some of them can be $7 \mathrm{ft}$ tall. Parents don't want them sat around in a front room all weekend and transport is often an issue - if mum and dad don't have an estate car it can be difficult to move them. (Gail Dudson, Director of Beverley Chamber Music Festival, quoted in Sutcliffe, 2004: 1)

Kids used to be bussed in to rehearsals with ensemble groups. Now their parents have to take them. If you're going to be a tuba player, your parents have got to have a car. (Keith Griffin, Director of Tŷ Cerdd Music Centre, Cardiff, quoted in Clark 2006: 13)

In the case study local authority, instrumental tuition took place in school, so it would have been necessary for music service pupils to transport most instruments between home and school, either on foot or by public transport or private car. Given that the data included both 
home postcodes and schools attended, it was possible to calculate home-school distances for each pupil. The existence of this case study data - together with contextual figures subsequently obtained on instrument size and weight - enabled arguments such as those quoted to be tested, at least in the idiographic context of the case study authority. However, no 'off the shelf' technological solutions were available to realize the necessary calculations, leading to the development of several self-authored computer programs or 'scripts'.

In some earlier studies utilizing home-school distances (e.g. Burgess et al. 2006), straightforward geodesic (i.e. 'as the crow flies') distances were computed between the coordinates of pupils' homes and their schools. The main advantage of this approach was that it is straightforward to calculate these distances (using Pythagoras' theorem) and therefore reduce computer processing overheads when working with large data sets. However, a significant disadvantage is that geodesic distances can differ from 'real-world', land-based distances, particularly where individuals have to negotiate environmental impediments and the idiosyncrasies of the road network. More recently, it has been possible to obtain more accurate, 'real-world' measurements by making use of the Google Maps Distance application programming interface (API) (Kolobikhin 2011; Google 2015). This enables users to submit origin and destination postcodes and have the Google Maps server return an accurate distance, based on walking routes (i.e. taking into account records of footpaths and pavements held in the Google Maps database). Since this API is a 'cloudbased' service, local computer processing and data storage overheads remain low. Home and school postcodes were submitted to the Google Maps API using a specially written Perl script (drawing on source code by Kolobikhin 2011).

Weight and size data for musical instruments were initially hard to find. Published research studies, such as those by Dawson (1997) and Waddle and Loen (2003), have tended to focus on the physical properties of certain, 'speciality' instruments (e.g. historical examples) and do not routinely include the weights or dimensions of ancillary objects such as cases and bows. Conveniently, however, the product data listed by online retailer Amazon include both weight and dimensions. Moreover, Amazon sold examples of all of the musical instruments in the case study data. 'Scraping' refers to the process of automatically gathering data from web sites. As in this case, it typically involves additional processing to take data originally formatted for reading by humans and converting it to tabular formats that can be utilized within databases or spreadsheets. Weight and size data were 'scraped' from Amazon. co.uk using a second, bespoke Perl programme. Written permission from the company's customer services was obtained in advance, an important step since this kind of automated process can exert a potentially detrimental load on an organization's webserver. 
In total, information on 1005 instruments was collated. Instruments were grouped by type and median weight and dimensions identified for each. Employing median values avoided the skewing influence of instruments with extreme, outlying properties (e.g. child versions and 'outfits' containing additional accessories, such as stands and amplifiers). The weights and dimensions included cases/bags. This was important, since instruments are always transported in their cases. In some cases, Amazon included small accessories (such as tuners, cleaning materials and spare string sets) within the quoted weights. Again, this was useful since players typically store and transport these accessories in their cases/bags. Instruments with conventional variations in sizes (i.e. saxophone, violin, viola, cello and classical guitar) were averaged to produce one, 'typical' weight in the final list.

Amongst pupils who received tuition only whilst at primary school and for whom accurate tuition start and end dates were known (primary starters and finishers, $n=2308$ ), a global regression model revealed a small but statistically significant negative relationship between the total period of time over which tuition was received (in days) and the instrumental weight $\left(\beta=-9.42 ; S E=2.05 ; t=-4.6 ; p \leq 1 \times 10^{-5}\right)$. For this particular subset of pupils, homeschool distance was found to make a non-significant contribution to the model. The $R^{2}$ for this univariate model was small (0.09), indicating that many other factors were also likely to relate to total tuition duration. Nonetheless, this figure still suggests that around 1 per cent of total variance in tuition durations for primary school pupils in the case study could be accounted for through the weight of their instrument. Specifically, the coefficient estimate of -9.42 suggests that as instrument weight increased by $1 \mathrm{~kg}$, length of tuition reduced by 9.42 days. With larger instruments, the potential reduction of study time becomes quite large indeed. In the case of the $20 \mathrm{~kg}$ tuba, 188 days is only two days short of a full UK academic year.

Amongst music service pupils who commenced tuition on a known date during primary school and continued until a known date in secondary school (secondary continuers, $n=$ 452), home-school distance was found to be a statistically significant factor. However, instrument weight was found to be non-significant. This model was again able to account for around 1 per cent of variance in total duration of tuition $(\beta=-30.6 ; S E=14.4 ; t=-2.13 ; p=$ $<0.05)$. Whilst a low $R^{2}$ confirms that many other factors will have had an impact, it is still notable that an increase in home-school distance of $1 \mathrm{~km}$ was associated with a 30.6-day reduction in the total time spent in receipt of tuition on this instrument at secondary school.

The mean geodesic home-secondary school distance in England is $2.44 \mathrm{~km}$ (Burgess et al. 2006), with mean home-primary school distances considerably shorter. The two models 
presented above suggest that whilst home-school distances may not be a critical factor for the 'primary starters and finishers', once the secondary transition has taken place, the additional distances to school may begin to exert a greater influence on pupils' decisions to continue or cease tuition. That instrument weight was not a significant contributor in the 'secondary continuers' model suggests that as secondary school-aged pupils become physically bigger and stronger they may have been better able to transport larger instruments.

Yet these conclusions are influenced by the 'global' nature of the regression models employed. In other words, they assume that music service pupils faced common challenges relating to home-school distance and instrumental weight irrespective of where they lived in the case study authority. Given both the widely disparate prevailing socio-economic conditions outlined in previous sections and the theoretical imperatives surrounding 'resource boosters', such an assumption may not be entirely reasonable. Thus, the next step was to implement a 'local' regression model.

\section{Constructing a 'local' regression model using GWR}

GWR was developed by Fotheringham et al. (2002) as part of a contemporary trend to develop specialist statistical techniques for local spatial data. In GWR, the traditional global regression model is extended to take into account the geographical coordinates of each data point in a given sample. Instead of one 'global' set of model coefficients, many 'local' models are generated, each using only a subset of nearby data points. Moreover, the contribution made by each data point in the subset is weighted so that those nearest have a stronger influence on a coefficient's value. One of GWR's key strengths is that it can be used to explore spatially referenced data for 'localised exceptions or deviations from global trends' (Grose et al. 2008: 11). A second key strength is that the regression coefficients associated with each local model can be mapped, enabling a researcher to assess visually the strength of association between predictor and outcome variables for each region of the study area (Fotheringham et al. 2002). For this reason, GWR has great potential for use in exploratory analysis since it can help the researcher to ask better, more focused questions relating to the area under study.

In the following example, a local regression model is presented which sheds further light on the relationship between instrument weight and total tuition time with the case study data. Amongst the 'primary starters and finishers' model reported above, a $1 \mathrm{~kg}$ increase in instrumental weight was associated with a 9.42-day reduction in the total time over which 
tuition was received. In the example below, GWR enables us to consider whether this relationship remained constant across the whole case study area or whether it varied spatially. A 500-m 'bandwidth' was specified, meaning that each local GWR model was calculated using a subset of data points whose coordinates fell within a $500 \mathrm{~m}$ radius. The contribution of individual data points was weighted using a Gaussian kernel. In other words, data points lying further away in each subset made progressively smaller contributions in line with the bell curve.

As in global regression, each coefficient in a local, GWR model is associated with a $t$ score and an assessment of statistical significance. In this case, the GWR routine revealed two specific areas of the case study local authority featuring a significantly stronger relationship between instrument weight and total tuition time. These are marked as zones ' 1 ' and ' 2 ' in Figure 2. In zone 1, the local models featured coefficient values for instrument weight between -25.16 and -21.63 . In zone 2 , the coefficients lay between -35.18 and -23.34 . It is clear that in both zones, these coefficients differ markedly from the value of -9.42 associated with the global model reported above. In the case of zone 2, the local model was also able to account for considerably more variance in tuition duration than the global model; the mean $R^{2}$ value for the local models in this zone was 0.12 .

In line with the exploratory nature of GWR, the next task was to consider whether this stronger negative relationship could be explained with reference to prevailing environmental and social factors. As an example, Figure 2 also plots four further data sets: (1) topographical height/contour data, (2) levels of income deprivation, again drawing on IMD 2010, (3) levels of vehicle ownership and (4) the prevalence of local access points to public transport. In the latter three plots, darker shading is associated with higher values, e.g. higher IMD 2010 income deprivation scores in (2), higher percentages of households with access to a vehicle in (3) and greater numbers of bus stops and railway stations in (4).

Figure $2 \mathrm{~b}$ reveals that zones 1 and 2 do not take in the most income deprived areas locally. However, both zones do have higher levels of income deprivation relative to neighbouring areas. In zone 1, around 20 per cent of households lacked access to a vehicle, whilst the figure was around 25 per cent in zone 2. Yet Figure 2c reveals that other local areas had even lower levels of vehicle ownership. At first glance, then, there would seem to be other, more likely areas to exhibit such strongly negative relationships, i.e. those towards the south-west of the area shown in Figure 2c. Nonetheless, comparison with Figure 1 confirms that these other areas attracted fewer music service participants to begin with (a concerning issue in itself of course, as noted above). Therefore, what appears to make zones 1 and 2 
distinct is that take-up of music service tuition was relatively high, but this tuition tended to be terminated sooner than in other, similarly high-recruiting areas. Both of these zones lay some $4-5 \mathrm{~km}$ from the town centre, and their suburban settings were reflected in slightly lower levels of public transport provision (see Figure $2 d-$ the town centre is on the central southern edge of the area). It is possible that the combination of slightly lower access to both vehicles and public transport, along with slightly higher levels of income deprivation, were enough to 'tip the balance' in such a way that the material influence of instrument weight on pupils' ability to continue their tuition increased. In contrast, in areas with greater levels of vehicle ownership and lower levels of income deprivation, this same influence was weaker, as evidenced by smaller, non-statistically significant coefficient values in the local models. In theoretical terms, these 'resource boosters' had been effective in ameliorating the potential barriers to accessing music service tuition.

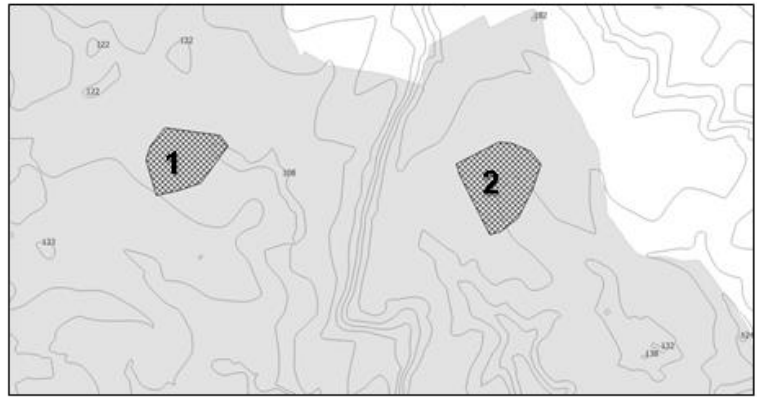

(a) Contour data

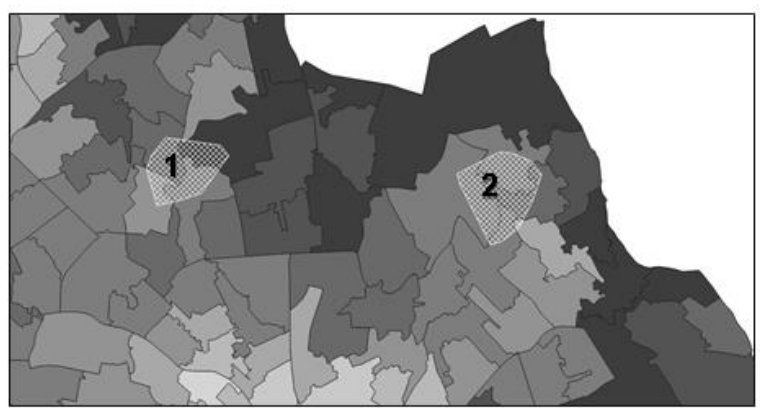

(c) Levels of vehicle ownership

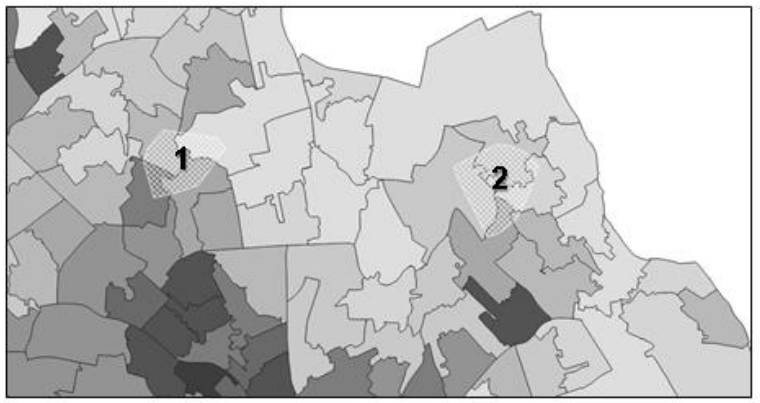

(b) Income deprivation

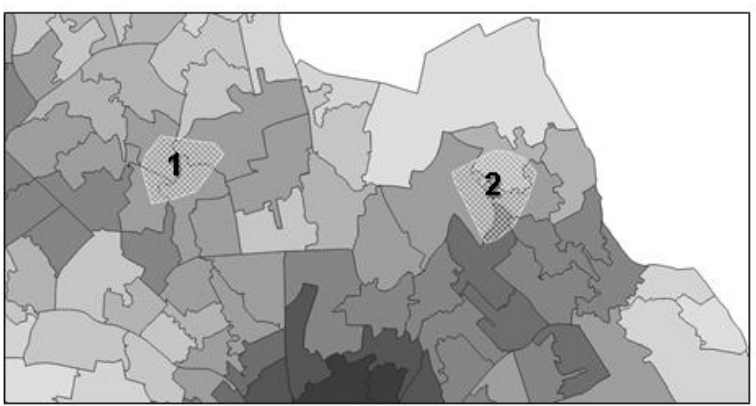

(d) Density of bus stops etc

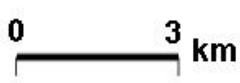

Figure 2: Zones '1' and '2' highlight areas of the case study local authority where a GWR 'local' regression model resulted in statistically significant coefficients for instrument weight. These zones are shown along with contextual contour data (a), levels of income deprivation (b), vehicle ownership (c) and density of bus stops and other public transport 'access points' (d). In plots (b-d), darker shading is associated with higher values. 
Of the two, it was zone 2 which has the strongest negative relationship between instrument weight and total duration of tuition. This may be partly explained by local topographical factors. Zone 1 lies between 105 and 110m above sea level, whereas zone 2 was located on a high plateau some 160 to $180 \mathrm{~m}$ above sea level. As can be seen in Figure 2a, access to/from zone 2 from elsewhere involves ascending/descending one of a number of steep hills. It is possible that this factor might further compound problems transporting heavier instruments in an area already associated with lower levels of vehicle ownership.

Overall, this local model offers a great deal more information, and generates many more questions and possibilities, than its global equivalent. Nonetheless, GWR remains an exploratory technique and is subject to considerable ongoing methodological development (e.g. Qu and Wu 2011). Many aspects of the case study data presented above could benefit from further GWR analysis, and this will inform the next stage of the research. In particular, more sophisticated regression models are envisaged which include not only measures of vehicle ownership and access to local public transport, but also school census data on how pupils travel to school. It is hoped that these will be capable of accounting for higher levels of overall variance $\left(R^{2}\right)$ in instrumental tuition durations. It should also be possible to consider pupil age as a factor, given that older children may be capable of carrying heavier instruments for longer distances. Given the rapidity with which data is now being published at appropriately fine-grained levels of geospatial resolution (at least in the United Kingdom), it will also be important to continue to seek ever more accurate and nuanced proxy measures for underlying socio-economic advantage and/or disadvantage.

\section{Conclusions}

Geospatial tools, technologies and analysis techniques have much to offer musicians, music researchers and music educators. The intention within this article has been to outline this potential and offer practical examples of a series of specific technologies and tools drawn from a single case study. These have embraced 'off the shelf' open-source software, publicly available 'big' data sets, specialist programming libraries for geospatial analysis (also open source) and bespoke self-authored programming utilities for scraping data from the web. The various advantages and disadvantages of global versus local regression models have also been explored. With regard to the latter, and as is evident in Figure 2, the ability to superimpose plots of various socio-economic and environmental factors over statistically significant GWR coefficients offers the researcher and musician enormous potential. For instance, it is possible to imagine a future scenario when a sufficiently detailed 'sound map' 
might be superimposed in this way, enabling spatially varying relationships to be considered within the context of not only geographical, but also sonic space.

As was outlined at the outset of this article, there is evidence in the literature to suggest that practitioners are responding imaginatively to the creative and technical opportunities that these tools offer. It is hoped that this article might stimulate further consideration of the possibilities. One excellent recent example of this coming together of practitioners on the basis of shared interests in music, sound, space and technology was the July 2015 symposium 'Art and Sound: Place. Art. Life' held in Leicester, England (Richardson and Rossiter 2015). As tools, techniques and data continue to be made available, it is hoped that such interdisciplinary collaborations will become the norm.

\section{References}

Artservice (2005), Endangered Species Evaluation: Phase 2 Report, Hereford: Artservice.

Artservice (2006), Endangered Species Evaluation Survey 2006 for Youth Music, Hereford: Artservice.

Barber, J. F. (2015), 'Soundscapes, soundwalks, sound maps, transects. (Weblog) Radio Nouspace', 27 December, http://www.dtc-wsuv.org/radionouspace/index.php/email/. Accessed 26 August 2016.

Barroso, J., Fernández-Quintanilla, C., Ruiz, D., Hernaiz, P. and Rew, R. J. (2004), 'Spatial stability of Avena sterilis ssp ludoviciana populations under annual applications of low rates of imazamethabenz', Weed Research, 44:3, pp. 178-86.

BERA (2011), Ethical Guidelines for Educational Research, London: British Education Research Association.

Berry, K. H., Coble, A. A., Yee, J. L., Mack, J. S., Perry, W. M., Anderson, K. M. and Brown, M. B. (2015), 'Distance to human populations influences epidemiology of respiratory disease in desert tortoises', The Journal of Wildlife Management, 79:1, pp. 122-36.

Bivand, R. S., Hauke, J. and Kossowski, T. (2013), 'Computing the Jacobian in Gaussian spatial autoregressive models: An illustrated comparison of available methods', Geographical Analysis, 45:2, pp. 150-79.

Bivand, R. S. and Piras, G. (2015), 'Comparing implementations of estimation methods for spatial econometrics', Journal of Statistical Software, 63:18, pp. 1-36.

Blanco-Moreno, J. M. and de la Cruz Rot, M. (2015), 'Syrjala \{ecespa\}: Syrjala's test for the difference between the spatial distributions of two populations', https://cran.rproject.org/web/packages/ecespa/index.html. Accessed 8 July 2015.

Born, G. and Devine. K. (2015), 'Music technology, gender, and class: Digitization, educational and social change in Britain', Twentieth-Century Music, 12:2, pp. 135-72.

Burgess, S., Briggs, S., McConnell, B. and Slater, H. (2006), School Choice in England: Background Facts, Bristol: Bristol Institute of Public Affairs, University of Bristol. 
Clark, R. (2006), 'The oboe, French horn and tuba', The Western Mail, 28 November, p. 13.

Cleave, S. and Dust, K. (1989), A Sound Start: The Schools' Instrumental Music Service, Windsor: NFER-Nelson.

Clements, A. and Guertin, L. (2016), 'Teaching world music with geospatial technology', https://sites.psu.edu/geospatialmusic. Accessed 17 August 2016.

Dawson, W. J. (1997), 'Common problems of wind instrumentalists', Medical Problems of Performing Artists, 12:4, pp. 107-11.

Deane, K., Holford, A., Hunter, R. and Mullen, P. (2015), The Power of Equality 2: Final Evaluation of Youth Music's Musical Inclusion Programme 2012-2015, London: National Foundation for Youth Music/Sound Sense.

Exeter, D. J., Rodgers, S. and Sabel, C. E. (2014), “"Whose data is it anyway?" The implications of putting small area-level health and social data online', Health Policy, 114:1, pp. 88-96.

Field, A., Miles, J. and Field, Z. (2013), Discovering Statistics Using R, London: Sage.

Fielding, N. G. and Fielding, J. L. (2015), 'Emergent technologies in multimethod and mixed methods research: Incorporating GIS and CAQDAS', in S. HesseBiber and R. Burke Johnson (eds), The Oxford Handbook of Multimethod and Mixed Methods Research Inquiry, New York: OUP, pp. 561-82.

Fotheringham, S. A., Brunsdon, C. and Charlton, M. (2002), Geographically Weighted Regression: The Analysis of Spatially Varying Relationships, Chichester: Wiley.

George, A. L. and Bennett, A. (2005), Case Studies and Theory Development in the Social Sciences, Cambridge, MA: MIT Press.

Goodwin, M. (2004), 'The scaling of "urban" policy: Neighbourhood, city or region?', in C. Johnstone and M. Whitehead (eds), New Horizons in British Urban Policy: Perspectives on New Labour's Urban Renaissance, Aldershot: Ashgate, pp. 173-84.

Google (2015), 'The Google Maps distance matrix API', https://developers.google.com/maps/documentation/distance-matrix/intro?hl=en._Accessed 16 December 2015.

Grőmping, U. (2006), 'Relative importance for linear regression in R: The package relaimpo', Journal of Statistical Software, 17:1, pp. 1-27.

Grose, D., Brunsdon, C. and Harris, R. (2008), Introduction to Geographically Weighted Regression $(G W R)$, Lancaster: University of Bristol and University of Lancaster.

Hallam, S. P. (1985), 'The development and influence of instrumental activity in school during the twentieth century', MA dissertation, London: University of London (Institute of Education).

Hallam, S. and Prince, V. (2000), Research into Instrumental Music Services, Research Report 229, London: Department for Education and Employment.

Hallam, S., Rogers, L. and Creech, A. (2005), Survey of Local Authority Music Services 2005, Nottingham: Department for Education and Skills. 
Hauger, D., Schedl, M., Košir, A. and Tkalčič, M. (2013), 'The Million Musical Tweets Dataset: What we can learn from microblogs', 14th International Society for Music Information Retrieval Conference (ISMIR 2013), Curitiba, Brazil, November 2013.

Hille, A. (2015), How a Universal Music Education Program Affects Time Use, Behaviour, and School Attitude, Berlin: German Socio-Economic Panel.

Himonides, E. (2016), 'Big data and the future of education: A primer', in A. King and E. Himonides (eds), Music, Technology and Education: Critical Perspectives, Abingdon: Routledge, pp. 243-56.

Himonides, E. and Purves, R. (2010), 'The role of technology', in S. Hallam and A. Creech (eds), Music Education in the 21st Century in the United Kingdom: Achievements, Analysis and Aspirations, London: Institute of Education, pp. 123-40.

Huber, C. G., Grabowski, T. B., Patiño, R. and Pope, K. L. (2014), 'Distribution and habitat associations of juvenile common snook in the lower Rio Grande, Texas, Marine and Coastal Fisheries', Dynamics, Management, and Ecosystem Science, 6:1, pp. 170-80.

Knopke, I. (2005), 'Geospatial location of music and sound files for music information retrieval', 6th International Conference on Music Information Retrieval (ISMIR 2005), London, 11-15 September 2005, pp. 29-33.

Kolobikhin, A. (2011), 'Google matrix distance, Google API Examples', https://sites.google.com/site/akolobikhin/software/google-api-1/google-api-examples/perl/googlematrix-distance. Accessed 21 February 2013.

LaJeunesse, S. (2011), 'Not your parent's music lessons', Penn State Outreach Magazine, Spring 2011, p. 25.

Lloyd, C. D. (2010), Spatial Data Analysis, New York: Oxford University Press.

Lund, J. (2007), 'Musicology: Mapping music and musicians', in D. Sinton and J. Lund (eds), Understanding Place: GIS and Mapping Across the Curriculum, Redlands, CA : ESRI Press, pp. 259-68.

Mainwaring, J. (1951), Teaching Music in Schools, London: Paxton.

Martin, D. (2004), 'GEOG3025 census and neighbourhood analysis: Confidentiality and social implications - 2003-04',

http://www2.geog.soton.ac.uk/users/leungs/GEOG3025/doc/Confidentiality_and_soc_imps_0304.d oc. Accessed 22 January 2014.

McAdam, B. J., Grabowski, T. B. and Marteinsdottir, G. (2010), 'Testing for differences in spatial distributions from telemetry data', Fisheries Research, 127-128, pp. 148-53.

McLennan, D., Barnes, H., Noble, M., Davies, J. and Garratt, E. (2011), The English Indices of Deprivation 2010, London: Department for Communities and Local Government.

Mitchell, J. C. (2006), 'Case and situation analysis', in T. Evens and D. Handelman (eds), The Manchester School: Practice and Ethnographic Praxis in Anthropology, New York: Berghahn Books, pp. 23-44.

Moore, J. L., Joachims, T. and Turnbull, D. (2014), 'Taste space versus the world: An embedding analysis of listening habits and geography', 15th International Society for Music Information Retrieval Conference, Taipei, Taiwan, 27-31 October 2014. 
Müllensiefen, D., Gingras, B., Musil, J. and Stewart, L. (2014), 'The musicality of non-musicians: An index for assessing musical sophistication in the general population', PLOS ONE, 9:2.

Ofsted (2004), Provision of Music Services in 15 Local Education Authorities, London: Ofsted.

Parcel, T. and Dufur, M. J. (2001), 'Capital at home and at school: Effects on student achievement', Social Forces, 79:3, pp. 881-912.

Parcel, T. and Hendrix, J. A. (2014), 'Family transmission of social and cultural capital', in J. Treas, J. Scott and M. Richards (eds), Wiley-Blackwell Companion to the Sociology of Families, Hoboken, NJ: Wiley, pp. 361-81.

Pill, M. (2007), 'What rationales are driving neighbourhood governance initiatives in the US and the UK', 'The Vital City': European Urban Research Association 10th Anniversary Conference, University of Glasgow, 12-14 September.

Prebble, T. (2010), 'Sound Maps. (Weblog) Music of Sound', 10th September, http://www.musicofsound.co.nz/blog/sound-maps. Accessed 26 August 2016.

Price, S. D. (2011), Endangered Phrases: Intriguing Idioms Dangerously Close to Extinction, New York: Skyhorse.

Purves, R. (2012), 'Technology and the educator', in G. McPherson and G. Welch (eds), The Oxford Handbook of Music Education, vol. 2, New York: Oxford University Press, pp. 457-75.

Purves, R. (2016), “"The Ten Percent": Young people's access to publicly-funded instrumental music tuition in England: Findings from an idiographic geographical case study', International Society for Music Education Research Commission Seminar, 18-22 July 2016, London: Paul Hamlyn Foundation.

Qiu, X. and Wu, S. (2001), 'Global and local regression analysis of factors of American College Test (ACT) score for public high schools in the state of Missouri', Annals of the Association of American Geographers, 101:1, pp. 63-83.

Richardson, J. and Rossiter, L. (eds) (2015), 'Art and sound: Place. Art. Life Symposium Programme', 4 July 2015, Phoenix Square and Curve Theatre, Leicester, http://artandsoundsymposium.com/wpcontent/uploads/2015/07/artsoundprogramme2015.compressed.pdf. Accessed 22 September 2016.

Sarkar, S., James, J., Fuller, T., Kelley, C., Garson, J. and Mayfield, M. (2005), 'Effectiveness of environmental surrogates for the selection of conservation area networks', Conservation Biology, 19:3, pp. 815-24.

Sebastian, R. E. (2015), 'If you like our sound, stick around: Buskers of the French Quarter', MA Dissertation, Wichita: Department of Anthropology, Wichita State University.

St John, P. and Richardson, D. (1996), Methods of Presenting Fieldwork Data, Sheffield: Geographical Association.

Stollery, P. (2005), 'Gordon Soundscape', http://homepages.abdn.ac.uk/wae006/gordonsoundscape.co.uk/. Accessed 26 August 2016.

Stone by Stone (2012), Identification of Cold Spots for the Musical Inclusion Programme in Cornwall, Cornwall: Cornwall Youth Music Action Zone.

Sutcliffe, R. (2004), 'The double bass hits a low note', The Yorkshire Post, 17 September, p. 1. 
Sutton, T. (2016), 'Promoting and using QGIS for the enterprise', GQIS Blog post, 23 April, http://blog.qgis.org/2016/04/23/promoting-and-using-qgis-for-the-enterprise. Accessed 22 September 2016.Syrjala, S. E. (1996), 'A statistical test for a difference between the spatial distributions of two populations', Ecology, 77:1, pp. 75-80.

Thomson, W. (1989), 'Instrumental music teaching in schools 4: The future of peripatetic teaching', Music Teacher, 68:4, pp. 40-41.

Tobler, W. (1970), 'A computer movie simulating urban growth in the Detroit region', Economic Geography, 46:2, pp. 234-40.

UK Data Service (2010), 'Office for National Statistics Postcode Directory, August 2010 version', http://census.edina.ac.uk. Accessed 25 February 2011.

Van den Eynden, V., Corti, L., Woollard, M., Bishop, L. and Horton, L. (2011), Managing and Sharing Data: Best Practice for Researchers, 3rd ed., Essex: UK Data Archive.

Waddle, J. R. and Loen, J. S. (2003), 'Weights of violin, viola, and cello', Catgut Acoustical Society Journal, 4:8, pp. 32-36. 